\title{
PERCEPÇÕES DO AGENTE COMUNITÁRIO DE SAÚDE SOBRE SUA ATUAÇÃO NA ESTRATÉGIA SAÚDE DA FAMILIA
}

Daíla Timbó Oliveira ${ }^{1}$, Paulo Jorge de Oliveira Ferreira², Larissa Bento de Araújo Mendonçaª, Helenir da Silva Oliveira ${ }^{4}$

\begin{abstract}
RESUMO: O estudo teve por objetivo descrever a percepção de Agentes Comunitários de Saúde acerca do seu processo de trabalho na Estratégia Saúde da Família. Trata-se de pesquisa exploratório-descritiva de abordagem qualitativa na qual participaram oito sujeitos, um de cada unidade com Estratégia Saúde da Família do Município de Quixadá - Ceará. Os dados foram coletados em 2011 por meio de entrevista; os depoimentos foram submetidos à leitura exaustiva e à análise de conteúdo de Bardin, dos quais emergiram seis categorias. Identificou-se a existência de relação positiva entre os Agentes Comunitários de Saúde e os enfermeiros das unidades e que a falta de insumos geram entraves ao desempenho adequado das atividades desses trabalhadores. É fundamental que o enfermeiro tenha sensibilidade para identificar as dificuldades apresentadas pelos agentes no que diz respeito ao seu cotidiano de trabalho.

PALAVRAS-CHAVE: Enfermagem; Saúde da família; Atenção primária à saúde; Auxiliares de saúde comunitária.

\section{COMMUNITY HEALTH ASSISTANTS' PERCEPTIONS ABOUT THEIR ROLE IN THE FAMILY HEALTH STRATEGY}

ABSTRACT: The study aimed to describe community health assistants' perception of their work processes in the Family Health Strategy. It is exploratory-descriptive research with a qualitative approach. Eight people participated, one from each of the Family Health Strategy units in the town of Quixadá in the state of Ceará. The data was collected in 2011 through interviews: the statements were submitted to close reading and Bardin's content analysis, from which six categories emerged. The study showed the existence of a positive relationship between community health assistants and the nurses in the health units, and that a shortage of materials hindered adequate performance of these workers' activities. It is fundamental that the nurse should be sensitive to identifying the difficulties mentioned by the assistants concerning their daily work routines.

KEYWORDS: Nursing; Family health; Primary healthcare; Healthcare assistants.

\section{PERCEPCIONES DEL AGENTE COMUNITARIO DE SALUD ACERCA DE SU ACTUACIÓN EN LA ESTRATEGIA SALUD DE LA FAMILIA}

RESUMEN: El estudio tuvo el objetivo de describir la percepción de Agentes Comunitarios de salud acerca de su proceso de trabajo en la Estrategia Salud de la Familia. Es una investigación exploratorio-descriptiva de abordaje cualitativo de la cual participaron ocho sujetos, un de cada unidad con Estrategia Salud de la Familia del municipio de Quixadá - Ceará. Los datos fueron recogidos en 2011 por medio de entrevista; las deposiciones fueron sometidas a la lectura exhaustiva y al análisis de contenido de Bardin, de los cuales surgieron seis categorías. Se identificó la existencia de relación positiva entre los Agentes Comunitarios de Salud y los enfermeros de las unidades y que la falta de insumos genera trabas al desempeño adecuado de las actividades de eses trabajadores. Es fundamental que el enfermero tenga sensibilidad para identificar las dificultades presentadas por los agentes acerca de su cotidiano de trabajo. PALABRAS-CLAVE: Enfermería; Salud de la Familia; Atención primaria a la salud; Auxiliares de Salud Comunitaria.

\footnotetext{
${ }^{1}$ Enfermeira. Especialista em Enfermagem Pediátrica e Neonatal. Coordenadora da Atenção Básica à Saúde do Município de Tamboril - CE ${ }^{2}$ Enfermeiro. Mestre em Enfermagem Fundamental. Professor do Curso de Graduação em Enfermagem da Faculdade Católica Rainha do Sertão- CE.

${ }^{3}$ Enfermeira do Hospital Geral Dr. César Cals. Mestranda em Enfermagem pela Universidade Federal do Ceará.

${ }^{4}$ Enfermeira. Professora do Centro de Ensino Tecnológico - Quixadá-CE.
}

Autor correspondente:

Larissa Bento de Araújo Mendonça

Universidade Federal do Ceará

Av. Rogaciano Leite, 200 - 60810-000 - Fortaleza-CE-Brasil

E-mail: laraenfermagem@hotmail.com
Recebido: 20/09/2011

Aprovado: 26/01/2012

Cogitare Enferm. 2012 Jan/Mar; 17(1):132-7 


\section{INTRODUÇÃO}

Há mais de duas décadas o Brasil implantou a Estratégia de Saúde da Família (ESF) com o objetivo de melhorar a assistência à saúde no nível básico. Neste contexto, surgiu o Agente Comunitário de Saúde (ACS) com papel fundamental nas ações básicas de saúde, promovendo a saúde e melhorando a qualidade de vida da população(1).

A ESF propõe, essencialmente, inovações na organização do processo produtivo por meio de mudanças no modo de operar o processo de trabalho, tendo como primazia o trabalho vivo em ato, o que significa uma aposta nas relações e a constituição de processos autoanalíticos de modo a possibilitar a superação do modelo hegemônico de atenção à saúde ${ }^{(2)}$.

O processo de qualificação do ACS se dá por meio de capacitação e treinamento para que realizem procedimentos, como medidas antropométricas, avaliação da imunização do indivíduo e, principalmente, o desenvolvimento de atividades educativas que visem a participação ativa da comunidade, além da realização de visitas domiciliares e reuniões em grupos com a comunidade ${ }^{(3-5)}$.

A atuação do ACS como facilitador comunitário tem passado por inúmeras dificuldades diante da sua trajetória, tais como encontrar respostas positivas aos encaminhamentos feitos, sobrecarga de trabalho, desvalorização profissional, além da perda da sua privacidade ${ }^{(6)}$. Este agente é quem observa as modificações ocorridas na vida do individuo morador da comunidade. Considerando que os resultados locais das políticas públicas de saúde surgem, naturalmente, a partir da ação conjunta de todos os envolvidos no processo saúde-doença, o ACS se consolida como agente transformador da saúde por meio de suas ações de trabalho, a partir da sua integração com a equipe de saúde.

Diante de sua importância na ESF, configura-se um desafio conhecer suas percepções acerca de seu trabalho na comunidade. Portanto, objetivou-se com este estudo descrever a percepção dos ACS acerca da sua atuação no cenário da ESF.

\section{MÉTODO}

Estudo exploratório-descritivo, de natureza qualitativa, realizado nas Unidades da ESF da área urbana do Município de Quixadá - Ceará. O Município de Quixadá fica situado na região Central do Estado do Ceará e uma das primeiras cidades brasileiras em que foi implementado o Programa de Agentes Comunitá- rios de Saúde (PACS); possui um total de 17 unidades do ESF, 8 na área urbana e 9 na área rural. O PACS é composto por um total de 146 ACS, desses 66 compõem as equipes da área urbana e 80 compõem as equipes da área rural.

Fizeram parte do estudo oito unidades da ESF da área urbana e um ACS de cada unidade totalizando oito entrevistados. Como critério de inclusão teve-se: ACS envolvidos em suas ações na comunidade e com tempo de trabalho superior a três anos, todos formalizaram a participação no estudo, o qual foi aprovado por Comitê de Ética em Pesquisa sob Protocolo n.20100158. Aos participantes foram atribuídos nomes de deuses.

A coleta de dados foi realizada no período de janeiro a fevereiro de 2011 por meio de uma entrevista semiestruturada mediante o uso de um instrumento composto por questões abertas que abordavam as características sociodemográficas dos ACS, o processo de trabalho na ESF e dados referentes à sua percepção sobre o cotidiano de trabalho.

Os depoimentos extraídos das entrevistas foram submetidos à leitura exaustiva. Na etapa seguinte, foi utilizada uma abordagem qualitativa, para a compreensão dos dados, utilizando-se a análise de conteúdo de $\operatorname{Bardin}^{(7)}$.

\section{RESULTADOS}

A caracterização dos sujeitos revelou que $87,5 \%$ eram do sexo feminino, casados (50\%) e residentes em imóvel próprio (87,5\%), a faixa etária variou entre 24 e 45 anos de idade e a renda mensal entre um à três salários mínimos. Quanto à escolaridade, $87,5 \%$ concluíram o ensino médio e 12,5\% têm nível superior incompleto.

Com relação à frequência das reuniões de grupo realizadas entre ACS e comunidade, de acordo com cada necessidade da população, $37,5 \%$ dos entrevistados realizam tais encontros quatro vezes por mês, $25 \%$ realizam uma vez por mês e $25 \%$ realizam duas vezes por mês. Os principais temas abordados nos encontros são: Doenças Sexualmente Transmissíveis, Tuberculose e Síndrome da Imunodeficiência Adquirida.

A análise das entrevistas permitiu o encontro de seis categorias, a seguir apresentadas:

\section{Categoria 1: Os ACS percebem positivamente a sua relação com o Enfermeiro da ESF}

Os relatos dos ACS refletem relações firmes constituídas com o enfermeiro de sua equipe de trabalho e são 
percebidas de forma positiva. Estas se estabelecem por meio de um vínculo de respeito profissional, amizade, acolhimento e humanização, o que favorece o compromisso ético e a integralidade no desenvolvimento de suas ações de trabalho, de acordo com os depoimentos que seguem:

Ela [enfermeira] não faz diferença entre os ACS. Ela é uma pessoa muito maravilhosa, amiga. [...] Ela é uma mãe para todas nós. Somos amigas e parceiras. (Artemis)

É uma relação aberta. É uma relação de irmão, apesar de ela ser enfermeira e a gente ACS; é uma relação saudável. (Zeus)

Minha relação com ela é amigável, muito boa e compreensiva. (Selene)

Categoria 2: A relação de confiança e disponibilidade entre o Enfermeiro e os ACS facilita o trabalho destes junto à comunidade

Por meio do presente estudo, foi possível identificar uma interação satisfatória, envolvente e construtiva entre o ACS e o Enfermeiro, que foi marcada principalmente, pela disponibilidade, resolubilidade de problemas, flexibilidade e o compartilhamento dessas com a comunidade.

Tudo que eu procuro e chego prá ela, ela me recebe bem, tem atenção de ouvir [...] ligo a qualquer hora e ela atende. A mãe chega até a mim e fala e eu chego até a enfermeira e falo prá ela. (Afrodite)

Ela sabe levar a comunidade e tem um vínculo muito forte com os ACS e com todos os profissionais do posto. Se a gente não tiver essa ligação forte e essa parceria, a gente não consegue realizar um trabalho bem feito. (Artemis)

Uma vez por mês temos a reunião da equipe e nessa hora que a gente resolve tudo. Ela tá disponivel a nos ajudar dentro da comunidade. Precisou, ela não mede dificuldade prá nos ajudar. (Selene)

Categoria 3: Os problemas comuns na saúde também afetam o trabalho dos ACS.

Os problemas mencionados nas falas dos ACS correspondem, principalmente, àqueles de cunho administrativo, como a falta de transporte veicular para realizar atividades fora da unidade de saúde e a ausência do enfermeiro, que é responsável por supervisionar e instruir a equipe do PACS.

A rotatividade do profissional de enfermagem. (Zeus)

A gente pode dizer que melhorou muito, antigamente, era pior. Faltava muito material de trabalho. (Atena)

É que temos a vontade de trabalhar, mas não temos condições. Assim, nós precisamos de visita domiciliar da enfermeira, mas não fazemos porque não temos transporte certo, e ela não vai a pé. Vai quando fica muito próximo a ela. (Ágata)

\section{Categoria 4: A construção de vínculo dos ACS com a comunidade}

Com base nos discursos expressados pelos ACS observou-se que os processos de construção de vínculos se dão por meio de relações de conquistas, de respeito, de amizade e, principalmente, de amor fraternal. Tudo isso demonstra compromisso e dedicação em seu trabalho. As dificuldades enfrentadas na criação dessas relações são superadas por meio do reconhecimento ao seu trabalho rotineiro e árduo, mas, ao mesmo tempo, envolvente e humano.

Acontece de eles estarem doentes e a gente sentir, sabe? Quer cuidar da criança, quer proteger mais do que a mãe. É como pai, é aquela proteção, aquele vínculo, não é desde a gestação. (Afrodite)

A gente se apega a essas familias e elas se tornam como familias da gente. Eu já chego e vou à cozinha, eu já tenho uma afinidade. Eu não deixo e eu não quero que ninguém tire ninguém da minha área. (Artemis)

A minha comunidade é muito boa prá se trabalhar, porque são pessoas carentes, pessoas que precisame pessoas que me conhecem desde quando nasci. É uma relação muito amigável. (Selene)

A fala seguinte mostra uma dificuldade na escuta do ACS com a comunidade. A entrevistada se mostra disponível em prestar seus serviços, independente de qualquer motivo de ordem geral ou pessoal que possa se apresentar entre os indivíduos envolvidos.

A gente é padre e eles se confessam, não é? E a gente 
tem que escutar, se você não parar e não escutar, eles dizem que a gente não presta, que a gente é isso, que a gente é aquilo. E a gente tem alguma rejeição e é normal, pra mim é normal. (Ares)

Categoria 5: Uma duplicidade de papeis desafia os ACS na manutenção do vínculo com a comunidade

As falas abaixo mostram as percepções dos ACS sobre a falta de reconhecimento por parte da população acerca de seu trabalho:

Não que lhe tratem mal, mas têm uma certa resistência $e$, dependendo dos casos, as pessoas já ficam mais fechadas. (Irene)

Eu chegava na casa dela e a porta estava fechada. Eu batia palma e ela dizia assim: 'não tem ninguém em casa fazendo aniversário aqui'. Toda vez ela dizia isso. (Artemis)

Na minha comunidade eles são pegajosos, pidões, perturba e aperreia demais. Eles viviam indo na minha casa. Eu já me mudei uma vez. Passei oito meses, morando em outra rua por conta das pessoas irem me procurar na minha casa. (Ares)

Categoria 6: A satisfação dos ACS com a comunidade onde atuam

Os sentimentos expressados pelos ACS nos revelam segurança, envolvimento pessoal e amor pelo trabalho, como descrevem as falas a seguir:

É muito gratificante, foi Deus que abençoou mesmo. Você tem aquela confiança e tem que ter; do ACS passar a ética envolvendo todo o problema. Sabe, aquilo fica sendo o nosso mundo. É bom você fazer esse trabalho. (Afrodite)

Eu adoro muito esse meu trabalho, sabia? Porque, antes de ser ACS eu trabalhava com uma associação, pra você ver como eu gosto do povo. É bom, a gente ganhar o dinheiro no final do mês, mas melhor ainda é chegar na casa ser bem recebida, ser reconhecida e as pessoas chamarem por você. É muito bom. (Artemis)

Tem a questão da ética, prá não comentar o que a gente ouve deles. É uma relação ótima, é muito gratificante. A gente, prá ser ACS, tem que gostar muito do trabalho. (Zeus)

É tão prazeroso alguém estar precisando do seu trabalho e você chegar e solucionar o problema dele. Isso é muito gratificante. (Atena)

\section{DISCUSSÃO}

A predominância de ACS do sexo feminino caracteriza a inserção feminina na força de trabalho nos atos em saúde, estando presente também entre outras profissões, como a Enfermagem. Esse perfil está relacionado com o papel de cuidador que a mulher desempenha na sociedade ${ }^{(8-9)}$. Com relação à idade, os ACS com mais idade tendem a deter um conhecimento maior acerca dos problemas da comunidade, com mais vínculo e laços de amizade, além de conflitos e inimizades. No entanto, em estudo realizado, os ACS reconheceram que a inserção de jovens poderia contribuir para a realização de mudanças no contexto da ESF, propiciando a reorganização do sistema ${ }^{(8)}$.

No que se refere ao nível de escolaridade, os ACS participantes do estudo corresponderam às exigências da Lei $n^{\circ} 10.507$ na qual estabelece que os ACS da ESF devam ter concluído pelo menos o Ensino Fundamental ${ }^{(10)}$. Essa realidade, possivelmente, reflete no trabalho desses profissionais, principalmente, nas ações programadas de atenção à saúde e melhoria qualidade de vida da comunidade assistida.

De acordo com as falas desveladas na Categoria 1, segundo autores ${ }^{(8)}$, a qualidade do trabalho em equipe depende do tipo de relação estabelecida entre as pessoas, os outros e as coisas. A prática do profissional enfermeiro enquanto instrutor/supervisor do PACS é essencialmente comunicativa, sendo que há a necessidade de se auto-expressar, se conhecer e conhecer os semelhantes. A própria maneira de ser e agir em grupo conota um tipo de comunicação e relacionamento com as pessoas com quem se convive diariamente e até consigo mesmo.

Diante dos relatos, verifica-se pessoalidade ao se manifestarem, porém tal relação não é prejudicial, pois possibilita autenticidade e respeito mútuo, condições indispensáveis ao surgimento e a manutenção de uma boa relação interpessoal.

$\mathrm{Na}$ Categoria 2, o conteúdo dos relatos demonstra uma parceria que vem ocorrendo de forma articulada e até planejada, em que o enfermeiro possui estreita relação com a equipe do PACS. Isso facilita o encaminhamento das ações estratégicas e a sua implementação 
na comunidade cujo objetivo é baseado nas necessidades das famílias que a compõem.

De acordo com pesquisadores ${ }^{(11)}$, o trabalho em equipe da ESF permite a continuidade do acompanhamento das famílias e maior envolvimento com as pessoas. Assim, é importante que seus membros tenham um bom relacionamento em equipe. Dentre seus integrantes, o ACS é o que se encontra mais próximo da população, caracterizando-se como elemento fundamental de ligação entre a comunidade e a equipe da ESF, levando os problemas locais levantados para serem discutidos em conjunto. Nesses relatos, percebe-se que existe uma preocupação mútua por parte do ACS e do enfermeiro para que o usuário seja atendido na unidade de saúde com agilidade e resolubilidade. Além disso, fica evidente que o profissional enfermeiro retribui essa assistência colaborando com os pedidos dos ACS e buscando a resolução das necessidades da comunidade.

As falas desveladas na Categoria 3 revelam que dificuldades administrativas podem gerar grandes impactos nas ações de cuidados a serem desenvolvidas na comunidade assistida pelos ACS. Diante disso, percebese a real necessidade de fortalecimento do trabalho em equipe e a criação de vínculo com a população.

A população pode ser exposta a riscos e os funcionários se sentem insatisfeitos por não desempenharem seu trabalho com eficiência quando não há planejamento das atividades ou descontinuidade nas ações de saúde. Esses fatos desmotivam a equipe no desempenho de seu trabalho ${ }^{(4)}$.

Diante desses aspectos, pode-se ressaltar que, embora seja um campo de trabalho recente e que a cada ano vem ganhando mais em consistência e importância, as atividades desenvolvidas pelos ACS não estão isentas de dificuldades comuns no âmbito da saúde (desorganização, falta de material, grande exposição dos profissionais a riscos), porém a forte vontade de ajudar a comunidade parece estar por trás da persistência desse grupo profissional. Depreende-se, então, que as vinculações bem constituídas garantem o envolvimento e compromisso profissional dos ACS.

$\mathrm{Na}$ analise da Categoria 4 percebe-se que o estabelecimento de vínculo, para os profissionais de saúde, deve-se primeiramente a conquista da confiança da população. Muitas vezes, esses profissionais passam a ser uma referência ao paciente, chegando, até mesmo, a ser participante de seu tratamento ou ser seu confidente. Assim, o estabelecimento de vínculo é a criação de laços, compromissos e corresponsabilidades entre os ACS e a população ${ }^{(1)}$.
Com relação à comunicação, em alguns estudos realizados $^{(12)}$ menciona-se que se deve atentar às relações interpessoais para que essa venha a contribuir nas discussões das equipes de saúde sobre as necessidades de cada família. Identifica-se hoje como estratégia, o diálogo ou mesmo a conversa como instrumento de trabalho e do apoio social.

O modelo de atenção à saúde aponta princípios claros ao alcance dos objetivos fundamentais, como a construção de vínculos entre os agentes do sistema de saúde e a população a fim de dar sustentação às ações de atenção integral à saúde ${ }^{(12)}$.

$\mathrm{Na}$ Categoria 5, os ACS revelam algumas dificuldades encontradas na sua relação com a comunidade. $\mathrm{O}$ contato com a população gera intenso envolvimento pessoal e desgaste emocional para o ACS. É identificada, ainda, ambiguidade nas emoções vivenciadas por esse profissional: no constante trabalho com a população, entrada de seu domicílio e vida privada; conhecimento das demandas e impossibilidades de sua ação ${ }^{(1)}$.

Um dos critérios para a seleção dos ACS é que, estes devem morar na mesma comunidade onde trabalham. Neste contexto, estudiosos ${ }^{(6)}$ referem que esta dupla inserção na comunidade obrigatoriamente os leva a desenvolverem um duplo papel: ser trabalhador de saúde e ser sujeito. Tal relação cria uma porosidade entre o trabalho e o viver no meio dessa sociedade.

As contradições apontadas no último discurso podem ser um sintoma da inexistência de espaços de reflexões sobre a realidade vivida de modo duplo pelo ACS, ou seja, ele é, ao mesmo tempo, agente de saúde e sujeito que a vive. Isto pode criar dicotomias, tanto nas suas próprias atitudes e pensamentos quanto na dos demais membros da comunidade. Portanto, sugere-se que se propiciem situações de reflexão e aprendizagem em torno dessas questões como forma de superação das contradições e que estas não se tornem entraves nas relações e vínculos tão fundamentais ao trabalho do ACS.

$\mathrm{Na}$ Categoria 6, os aspectos positivos do trabalho, citados pelos agentes, se resumiram, principalmente, na gratificação vinculada ao trabalho e no fato de cuidar, de estar próximo das famílias, de vigiar; apontando o perfil de um profissional que é útil à comunidade $\mathrm{e}$ satisfeito com o trabalho desenvolvido. Os ACS atribuem à sua função aspectos positivos voltados para a caridade e a possibilidade de conhecer as pessoas.

Um dos depoimentos apresenta a relação ética do profissional ACS. Conforme alguns pesquisadores ${ }^{(9)}$, este profissional tem acesso a muitas informações pessoais dos sujeitos da comunidade a qual presta as- 
sistência, uma vez que esses usuários, na maioria das vezes, expõem a sua situação de saúde e condições de vida primeiramente aos ACS, gerando conseqüentemente um dilema ético.

Em um estudo realizado em $2010^{(1)}$, os ACS mencionaram alguns problemas referentes à resistência dos moradores em relação ao seu trabalho, como a omissão de informações, recusa ao atendimento e visita domiciliar e a procura dos moradores por outros meios para conseguir atendimento na unidade de saúde, ao invés de solicitar ajuda aos ACS.

Em outro estudo, realizado em 2011, revelou que as seguintes facilidades foram apontadas pelos ACS para o trabalho em equipe: a construção das relações interpessoais, que se expressam por meio da possibilidade de discussão dos problemas cotidianos, liberdade para falar, comunicação e diálogo, atitudes de respeito, linguagem comum, disposição para aprender e união(2).

\section{CONSIDERAÇÕES FINAIS}

Foi possível identificar no estudo a existência de uma relação positiva entre o ACS e o enfermeiro da ESF. Evidenciou-se a presença de um forte vínculo entre esses trabalhadores quando os ACS enfatizam a existência de confiança e disponibilidade entre o enfermeiro e o mesmo.

O trabalho dos ACS é consagrado por possuir um papel essencial na difusão das informações entre comunidade e unidade de saúde, que só se tornam efetivas por meio da construção de um vínculo forte com a comunidade, deixando de serem percebidos somente como funcionários da saúde pública, passando a ser vistos como amigos ou membros da família.

É fundamental que o enfermeiro da ESF tenha sensibilidade para identificar as dificuldades apresentadas pelos ACS no que diz respeito ao seu cotidiano de trabalho. Essas dificuldades podem ser identificadas através da investigação permanente das condições de trabalho e resolutividade de problemas, para que se possam oferecer condições de trabalho adequadas para esses agentes de saúde.

\section{REFERÊNCIAS}

1. Cardoso AS, Nascimento MC. Comunicação no Programa Saúde da Família: o agente de saúde como elo integrador entre a equipe e a comunidade. Cienc. saude coletiva. 2010;15(1):1509-20.

2. Peres CRFB, Júnior ALC, Silva RF, Marin MJS. O Agente Comunitário de Saúde frente ao processo de trabalho em equipe: facilidades e dificuldades. Rev. esc. enferm. USP. 2011;45(4):905-11.

3. Brand CI, Antunes RM, Fontana RT. Satisfações e insatisfações no trabalho do agente comunitário de saúde. Cogitare enferm. 2010;15(1):40-7.

4. Santos KT, Saliba NA, Moimaz SAS, Arcieri RM, Carvalho ML. Agente comunitário de saúde: perfil adequado a realidade do Programa Saúde da Família. Cienc. saude coletiva. 2011;16(1):1023-8.

5. Santana JCB, Vasconcelos AL, Martins CV, Barros JV, Soares JM, Dutra BS. Agente comunitário de saúde: Percepções na estratégia saúde da família. Cogitare enferm. 2009;14(4):645-52.

6. Jardim TA, Lancman S. Aspectos subjetivos do morar e trabalhar na mesma comunidade. Interface. 2009;13(28):123-35.

7. Bardin L. Análide de conteúdo. $4^{\mathrm{a}}$ ed. Lisboa: Edições 70, 2009.

8. Galavote HS, Prado TN, Maciel ELN, Lima RCD. Desvendando os processos de trabalho do agente comunitário de saúde nos cenários revelados na Estratégia Saúde da Família no município de Vitória (ES, Brasil). Cienc. saude coletiva. 2011;16(1):231-40.

9. Ferraz L, Aerts DRGC. O cotidiano de trabalho do agente comunitário de saúde no PSF em Porto Alegre. Cienc. saude coletiva. 2005;10(2):347-55.

10. Brasil. Lei $\mathrm{n}^{\circ} 10.507$ de 10 de julho de 2002. Cria a profissão e dá outras providências. Diário Oficial da União, 10 jul. 2002.

11. Oliveira EM, Spiri WC. Programa Saúde da Família: a experiência de equipe multiprofissional. Rev. Saude Publica. 2006;40(4):727-33.

12. Santos LPGS, Fracolli LA. O Agente Comunitário de Saúde: possibilidades e limites para a promoção da saúde. Rev. esc. enferm. USP. 2010;44(1):76-83. 